\title{
Clearing the smoke: the science base for tobacco harm reduction-executive summary
}

\author{
Kathleen Stratton, Padma Shetty, Robert Wallace, Stuart Bondurant, editors
}

\section{Background}

Tobacco smoke is the cause of the most deadly epidemic of modern times. Smoking causes cancer (for example, lung, oral cavity, oesophagus, larynx, pancreas, bladder, kidney), chronic obstructive pulmonary disease (COPD), myocardial infarction, and stroke. The continuing toll of tobacco use has prompted the search for means of harm reduction for those who cannot or will not stop using tobacco. Numerous products that make implied or explicit claims to reduce the burden of smoking while allowing continued nicotine consumption are now entering the market. This report is concerned with the evaluation of these products.

Nearly one quarter of adult Americans - an estimated 47 million people-smoke cigarettes. ${ }^{1}$ Although this is far lower than the $42 \%$ recorded in 1965 , the decline in the rates of smoking among adults appears to have levelled off during much of the 1990 s. $^{2}$ In a recent survey, $12.8 \%$ of middle school children and $34.8 \%$ of high school students reported some form of tobacco use during the month prior to their being interviewed. ${ }^{3}$ The vast majority of smokers begin tobacco use during adolescence. ${ }^{4}$ However, $70 \%$ of smokers say they want to quit $^{5}$ and $34 \%$ of smokers make an attempt to quit each year. Thus, many but not all tobacco users find it very difficult to quit and continually expose themselves to known toxic agents.

Committee to Assess the Science Base for Tobacco Harm,

Reduction, Board on Health Promotion and Disease Prevention.

Washington, DC, USA

K Stratton

P Shetty

$\mathrm{R}$ Wallace

$S$ Bondurant

Correspondence to: Kathleen Stratton KStratto@nas.edu

This article was previously published by the National Academy Press, Institute of Medicine, 2001, and is reproduced with the permission of the publishers permission of the publishers 10029.html?onpi_webextral

\section{Definition of harm reduction}

For the purposes of this report, a product is harm reducing if it lowers total tobacco related mortality and morbidity even though use of that product may involve continued exposure to tobacco related toxicants. Many different policy strategies may contribute to harm reduction. However, this report focuses on tobacco products that may be less harmful or on pharmaceutical preparations that may be used alone or concomitantly with decreased use of conventional tobacco. The committee does not use the term "safer cigarette" in particular, in order to avoid leaving the impression that any product currently known is "safe". Every known tobacco containing product exposes the user to toxic agents; every pharmaceutical product can have adverse effects.

\section{History of efforts to reduce harm from cigarettes}

There have been many efforts in the past to develop less harmful cigarettes, none of which has proved to be successful. One of the first innovations with the promise of harm reduction was the development of cigarettes with filters. Filters attempt to reduce the amount of toxicants that go into the smoke inhaled by the smoker. The next major modification of cigarettes with safety implications was "low yield" cigarettes. These products emit lower tar, carbon monoxide (CO), and nicotine than other products as measured by the Federal Trade Commission (FTC) assay (the "smoking machine"). Many consumers believed, and still do, that these products pose less risk to health than other cigarettes.

However, data on the health impact of low yield products are conflicting, in part because of a lack of systematic study early in the introduction of the products. Most current assessments of morbidity and mortality suggest that low yield products are associated with far less health benefit, if any, than would be predicted based on estimates of reduced toxic exposure using FTC yields. In order to maintain the desired intake of nicotine, many smokers who changed to low yield products also changed the way they smoked (for example, compensated by inhaling more deeply than when smoking higher yield products). Thus, their exposure to tobacco toxicants is higher than would have been predicted by standardised assays and people who have continued to use these products have not significantly reduced their disease risk by switching to them. Moreover, widespread use of these products might have increased harm to the population in the aggregate if tobacco users who might otherwise have quit did not, if former tobacco users resumed use, or if some people who would otherwise not have used tobacco did so because of perceptions that the risk with low yield products was minimal.

\section{Types of exposure reduction products}

Tobacco and cigarette-like products have been introduced recently that, under measurement systems such as the FTC smoking machine, result in decreased emission of some toxicants compared to conventional tobacco products. Currently available products include tobacco with reportedly reduced levels of some carcinogens and cigarette-like products that deliver nicotine with less combustion than 
Table 1 Potential reduced exposure products (PREPS)

\begin{tabular}{|c|c|c|}
\hline Category & Descriptors & Examples \\
\hline Modified tobacco & $\begin{array}{l}\text { Reduced yield of selected } \\
\text { toxicants }\end{array}$ & $\begin{array}{l}\text { Advance }{ }^{\mathrm{TM}} \text {, low nitrosamine tobacco cigarettes, } \\
\text { Snus, reduced nitrosamine smokeless tobacco }\end{array}$ \\
\hline $\begin{array}{l}\text { Cigarette-like } \\
\text { products }\end{array}$ & $\begin{array}{l}\text { Less combustion than } \\
\text { cigarettes }\end{array}$ & $\begin{array}{l}\text { Premier }{ }^{\mathrm{TM}} \text { (off market) } \\
\text { Eclipse }^{\mathrm{TM}} \\
\text { Accord }^{\mathrm{TM}}\end{array}$ \\
\hline $\begin{array}{l}\text { Pharmaceutic al } \\
\text { products }\end{array}$ & $\begin{array}{l}\text { Nicotine replacement } \\
\text { Antidepressants that } \\
\text { reduce nicotine craving } \\
\text { Other medications }\end{array}$ & $\begin{array}{l}\text { Nicotine gum, patches, inhaler, nasal spray } \\
\text { Bupropion SR, nortriptyline } \\
\text { Nicotine antagonists, clonidine }\end{array}$ \\
\hline
\end{tabular}

cigarettes. Two classes of pharmaceutical products approved by the Food and Drug Administration (FDA) for short term use in smoking cessation might also be used for harm reduction. These include nicotine products, such as in patch, gum, inhaler, and nasal spray preparations, and a non-nicotine product that reduces the craving for tobacco. These cessation drugs could be used long term to maintain cessation or concomitantly with continued but decreased use of conventional tobacco products (table 1).

These tobacco and pharmaceutical products could potentially result in reduced exposure to toxicants. The committee uses "potentially" because whether exposure to tobacco toxicants is reduced depends on the user's behaviour, such as frequency and intensity of use. Reduced exposure, however, does not necessarily assure reduced risk to the user or reduced harm to the population. Therefore, and in order to avoid misinterpretation, the committee uses the generic phrase "potential reduced exposure products", or PREPs, when discussing the modified tobacco products, cigarette-like products (whether tobacco containing or not), or pharmaceutical products and medical devices (whether nicotine containing or not) used for their tobacco harm reduction potential. More such products are likely to be introduced in the near future, perhaps accompanied by claims that they are less harmful than conventional products.

The committee charge and assumptions The Institute of Medicine (IOM) convened a committee of experts to formulate scientific methods and standards by which PREPs (pharmaceutical or tobacco related) could be assessed. Four questions were imbedded within the charge given to the committee by the Food and Drug Administration (FDA) in December 1999. Where there are not yet answers, the committee was asked to outline the broad strategy by which the knowledge base might be assembled.

1. Does use of the product decrease exposure to the harmful substances in tobacco?

2. Is this decreased exposure associated with decreased harm to health?

3. Are there surrogate indicators of this effect on health that could be measured in a time frame sufficient for product evaluation?

4. What are the public health implications of tobacco harm reduction products?

The first three questions deal with the adequacy of current scientific methods to determine whether and to what extent these products reduce the risk of morbidity and mortality and the nature of the advice to give to citizens, health professionals, and others. The fourth question is important because it addresses the population impact of these products. That is, although a product might be risk reducing for an individual's health compared to conventional tobacco products, its use might not be harm reducing for the population as a whole. The fourth question is also important because the answer lays the groundwork for educational, policy, and regulatory actions.

The committee reviewed the literature and assessed the nature and availability of the data needed to evaluate the feasibility of tobacco harm reduction. Its review encompassed the major disease categories linked by scientific evidence to tobacco consumption, including cancer, cardiovascular disease, respiratory disease, reproductive and developmental disorders, and others. The report is offered to relevant federal and state regulatory and policy bodies, Congress, scientists and health care professionals, tobacco and pharmaceutical industries, and - most importantly - the public, who will have to decide whether or not to use these products.

The committee began with fundamental operating precepts, reiterating and reaffirming overwhelming scientific evidence and the conclusions of many scientific and policy advisory bodies:

Precept 1-Tobacco use causes serious harm to human health.

Precept 2-Nicotine is addictive.

Precept 3-The best means to protect individual and public health from tobacco harms are to achieve abstinence, prevent initiation and relapse, and eliminate environmental tobacco smoke exposure.

Precept 4-A comprehensive and authoritative national tobacco control programme, with harm reduction as one component, is necessary to minimise adverse effects of tobacco.

\section{Principal conclusions}

The committee does not evaluate specific PREPs in this report, since the currently available tobacco related PREPs in particular are most likely prototypes of limited life span. Under present regulatory conditions, tobacco related PREPs can be changed with little assessment and without disclosure of their contents. Therefore, the committee considered the types of PREPs currently or likely to become available in the foreseeable future. After reviewing a large body of scientific documents and data, hearing presentations from many scientific, regulatory and industrial interests, and publicly soliciting comments on the issues at hand, the committee reaches the following principal conclusions regarding the questions posed by the charge:

Conclusion 1-For many diseases attributable to tobacco use, reducing risk of disease by reducing exposure to tobacco toxicants is feasible. This conclusion is based on studies demonstrating that for many diseases, reducing tobacco smoke 
exposure can result in decreased disease incidence with complete abstinence providing the greatest benefit.

Conclusion 2-PREPs have not yet been evaluated comprehensively enough (including for a sufficient time) to provide a scientific basis for concluding that they are associated with a reduced risk of disease compared to conventional tobacco use. One narrow exception is the use of nicotine gum in one study for maintenance of cessation, described in chapters 8,13 , and 14. Carefully and appropriately conducted clinical and epidemiological studies could demonstrate an effect on health. However, the impact of PREPs on the incidence of most tobacco related diseases will not be directly or conclusively demonstrated for many years.

Conclusion 3-Surrogate biological markers that are associated with tobacco related diseases could be used to offer guidance as to whether or not PREPs are likely to be risk reducing. However, these markers must be validated as robust predictors of disease occurrence, and should be able to predict the range of important and common conditions associated with conventional tobacco products. Furthermore, the efficacy of PREPS will likely depend on user population characteristics (for example, those defined by sex, genetic susceptibility, ethnicity, tobacco history, and medical history).

Conclusion 4-Currently available PREPs have been or could be demonstrated to reduce exposure to some of the toxicants in most conventional tobacco products. Many techniques exist to assess exposure reduction, but the report contains many caveats about the use of all of them, including usually an unknown predictive power for harm.

Conclusion 5-Regulation of all tobacco products, including conventional ones as recommended in IOM, 1994, as well as all other PREPs is a necessary precondition for assuring a scientific basis for judging the effects of using PREPs and for assuring that the health of the public is protected. Regulation is needed to assure that adequate research (on everything from smoke chemistry and toxicology to long term epidemiology) is conducted and to assure that the public has current, reliable information as to the risks and benefits of PREPs. Careful regulation of claims is needed to reduce misperception and misuse of the products. If a PREP is marketed with a claim that it reduces (or could reduce) the risk of a specific disease(s) compared to the risk of the product for which it substitutes, regulation is needed to assure that the claim is supported by scientifically sound evidence and that pertinent epidemiological data are collected to verify that claim.

Conclusion 6-The public health impact of PREPs is unknown. They are potentially beneficial, but the net impact on population health could, in fact, be negative. The effect on public health will depend upon the biological harm caused by these products and the individual and community behaviours with respect to their use. Regulation cannot assure that the availability of risk reducing PREPs will lead to reduced tobacco related harm in the population as a whole. However, a regulatory agency can assure that data are gathered that would permit the population effects to be monitored. If tobacco use increases or tobacco related disease increases, these data would serve as a basis for developing and implementing appropriate public health interventions.

\section{Principal recommendations}

The committee believes that harm reduction is a feasible and justifiable public health policybut only if it is implemented carefully to achieve the following objectives:

- manufacturers have the necessary incentive to develop and market products that reduce exposure to tobacco toxicants and that have a reasonable prospect of reducing the risk of tobacco related disease;

- consumers are fully and accurately informed of all of the known, likely, and potential consequences of using these products;

- promotion, advertising and labelling of these products are firmly regulated to prevent false or misleading claims, explicit or implicit;

- health and behavioural effects of using PREPs are monitored on a continuing basis;

- basic, clinical, and epidemiological research is conducted to establish their potential for harm reduction for individuals and populations, and.

- harm reduction is implemented as a component of a comprehensive national tobacco control programme that emphasises abstinence oriented prevention and treatment.

Recommendations about future research needs are based on principal conclusions 1-4 and can be found in the following section. They flow primarily from material presented in section II of the report. Progress in these areas will permit the application of the principles of risk assessment to the evaluation of PREPs in the future. At present, judgement informed by incomplete science will be used to evaluate PREPs. However, immediate actions are required. Therefore, the committee makes recommendations that address principal conclusions 5 and 6 . These conclusions and recommendations are particularly intertwined, requiring immediate attention and swift action.

The effect of PREPs could be to increase or decrease tobacco related disease in the population. Assessing a positive public health impact will be difficult and will require extensive surveillance and research to ensure that the impact is positive. Even the strongest surveillance system could not alone provide minimal assurance of safety or protection of the public. Currently there is little public authority over tobacco products of any type. Whatever the current legal or regulatory posture with respect to these products, the committee realised that in order to obtain the best available scientific evaluation of emerging tobacco related PREPs and to provide the best advice on use of all PREPs to the public, some national authority over these PREPs is needed. Only a comprehensive programme of regulation and assessment including extensive 
premarket testing and surveillance offers a reasonable possibility of net gain in health from use of PREPs instead of conventional tobacco product use.

Therefore, the committee recommends development of a surveillance system to assess the impact of promotion and use of PREPs on the health of the public.

A national comprehensive surveillance system is urgently needed to collect information on a broad range of elements necessary to understand the population impact of tobacco products and PREPs, including attitudes, beliefs, product characteristics, product distribution and usage patterns, marketing messages such as harm reduction claims and advertising, the incidence of initiation and quitting and non-tobacco risk factors for tobacco-related conditions. There should be surveillance of major smoking related diseases as well as construction of aggregate population health measures of the net impact of conventional product and PREPs.

The surveillance system should consist of mandatory, industry furnished data on tobacco product constituents and population distribution and sales. Resources should be made available for a programme of epidemiological studies that specifically address the health outcomes of PREPs and conventional tobacco products, built on a robust surveillance system and using all available basic and clinical scientific findings.

The committee further recommends strengthened federal regulation of all modified tobacco products with risk reduction or exposure reduction claims, explicit or implicit, and any other products offered to the public to promote reduction in or cessation of tobacco use. The committee outlines 11 principles to govern the regulation of PREPs. The regulation proposed by this committee is narrowly focused on assuring that the products reduce risk of disease to the user and accumulating data that would indicate whether or not the products are harm reducing for the population in the aggregate. Other potential regulatory approaches to tobacco control are not addressed within this report.

The recommended regulatory structure builds on the foundation of existing food and drug law, with appropriate adaptations to take into account the unique history and toxicity of tobacco products. These principles envision testing and reporting for all tobacco products, approval of claims regarding reduced exposure and reduced risk regarding tobacco or cigarette-like products, and retention of current FDA regulation of pharmaceutical PREPs. Manufacturers of tobacco products and pharmaceuticals should be encouraged to develop and introduce new products that will reduce the burden of tobacco related disease. The regulatory system proposed in this report is not to be viewed in isolation. It is proposed as an essential component of a package of public health initiatives (including research, education, and surveillance) that this committee believes is necessary to realise whatever benefit tobacco and pharmaceutical product innovation can offer in reducing the nation's burden of tobacco related illness and death (see box 1).

\section{Research conclusions and} recommendations

Many fruitful research directions should be explored to strengthen the scientific basis for assessing harm reduction. In reviewing the range of scientific disciplines and disease areas, the committee specifically noted five general scientific issues: (1) description of the doseresponse relationship between tobacco smoke and/or constituent exposure and health outcomes; (2) identification and development of surrogate markers for disease; (3) the utility of preclinical research; (4) utility of short term clinical and epidemiological studies; and (5) the role of long term epidemiological studies and surveillance. The committee has reviewed the evidence available regarding these points and has described a research agenda to facilitate evaluation of the harm reduction potential of these products. This section summarises the committee's conclusions and recommendations for future research, which are elaborated in detail in section II of this report.

1. Currently available data allow estimation, albeit imprecise, of a dose-response relationship between exposure to whole tobacco smoke and major diseases that can be monitored for evaluation of harm reduction potential.

There are more than 4000 different chemicals in tobacco smoke; many of these are known to be toxic. Many of the mechanisms of pathogenesis attributed to tobacco use have been explicated, and in a few cases, causative tobacco constituents have been identified. In order to effectively evaluate the toxic effects of tobacco smoke and identify the primary causal agents, the toxic components of PREPs and comparison products must be identified and be disclosed. For the most part, the data are insufficient to accurately describe the relationship of tobacco use and disease formation at the level of detail that would establish all causal agents involved or the exact dose-response relationship. The characteristics of this relationship vary among diseases and are affected by differences in compensation and actual exposure and by interindividual or population differences. Consequently, the confidence with which the adverse effects or harm reduction potential of PREPs can be extrapolated, especially at low doses, is uncertain. Also, there is currently no evidence to support a threshold level of tobacco exposure below which no risk exists for any of the reviewed health outcomes.

In summary, current knowledge of the dose-response relationships is sufficient to support risk reduction through exposure reduction as a goal for the individual through the use of these various products. To date, these relationships are not defined well enough in terms of specific components of smoke to serve as a predictive tool for the effect a particular product will have on most health outcomes. However, a strong quantitative relationship between maternal tobacco exposure and the 
Box 1 Regulatory principles

Regulatory principle 1-Manufacturers of tobacco products, whether conventional or modified, should be required to obtain quantitative analytical data on the ingredients of each of their products and to disclose such information to the regulatory agency.

Regulatory principle 2-All tobacco products should be assessed for yields of nicotine and other tobacco toxicants according to a method that reflects actual circumstances of human consumption; when necessary to support claims, human exposure to various tobacco smoke constituents should be assessed using appropriate biomarkers. Accurate information regarding yield range and human exposure should be communicated to consumers in terms that are understandable and not misleading.

Regulatory principle 3-Manufacturers of all PREPs should be required to conduct appropriate toxicological testing in preclinical laboratory and animal models as well as appropriate clinical testing in humans to support the health related claims associated with each product and to disclose the results of such testing to the regulatory agency.

Regulatory principle 4-Manufacturers should be permitted to market tobacco related products with exposure reduction or risk reduction claims only after prior agency approval based on scientific evidence (a) that the product substantially reduces exposure to one or more tobacco toxicants and (b) if a risk reduction claim is made, that the product can reasonably be expected to reduce the risk of one or more specific diseases or other adverse health effects, as compared with whatever benchmark product the agency requires to be stated in the labelling. The "substantial reduction" in exposure should be sufficiently large that measurable reduction in morbidity and/or mortality (in subsequent clinical or epidemiological studies) would be anticipated, as judged by independent scientific experts. Regulatory principle 5-The labelling, advertising, and promotion of all tobacco related products with exposure reduction or risk reduction claims must be carefully regulated under a "not false or misleading" standard with the burden of proof on the manufacturer, not the government. The agency should have the authority and resources to conduct its own surveys of consumer perceptions relating to these claims.

Regulatory principle 6-The regulatory agency should be empowered to require manufacturers of all products marketed with claims of reduced risk of tobacco related disease to conduct postmarketing surveillance and epidemiological studies as necessary to determine the short term behavioral and long term health consequences of using their products and to permit continuing review of the accuracy of their claims.

Regulatory principle 7-In the absence of any claim of reduced exposure or reduced risk, manufacturers of tobacco products should be permitted to market new products or modify existing products without prior approval of the regulatory agency after informing the agency of the composition of the product and certifying that the product could not reasonably be expected to increase the risk of cancer, heart disease, pulmonary disease, adverse reproductive effects or other adverse health effects, compared to similar conventional tobacco products, as judged on the basis of the most current toxicological and epidemiological information. Regulatory principle 8-All added ingredients in tobacco products, including those already on the market, should be reported to the agency and subject to a comprehensive toxicological review.

Regulatory principle 9-The regulatory agency should be empowered to set performance standards (for example, maximum levels of contaminants; definitions of terms such as "low tar") for all tobacco products, whether conventional or modified, or for classes of products.

Regulatory principle 10-The regulatory agency should have enforcement powers commensurate with its mission, including power to issue subpoenas.

Regulatory principle 11 - Exposure reduction claims for drugs that are supported by appropriate scientific and clinical evidence should be allowed by the FDA. incidence of spontaneous abortions and intrauterine growth retardation leading to low infant birth weight has been documented extensively. This population is one in which the actual health effects of PREPs and potential for harm reduction may be most directly evaluated. Further discussion regarding dose-response can be found in the disease specific chapters in section II (chapters 12-16).

\section{Although candidate disease specific surrogate markers are currently available, further validation of these markers is needed. In addition, other} biomarkers that accurately reflect mechanisms of disease must be developed to serve as intermediate indicators of disease and disease risk.

Biomarkers are measurements of any tobacco constituent, tobacco smoke constituent, or effect of such a compound in a body fluid (including exhaled air) or organ. Although some biomarkers currently exist, these require further validation and more must be developed that have adequate sensitivity, specificity, and limited complexity and that quantitatively link biological exposure of tobacco smoke or specific constituents to disease induction or progression before the advent of clinically apparent disease. Validation and development of biomarkers will provide a stronger foundation by which to make scientific evaluations and regulatory decisions regarding PREPs.

Although no panel of markers can be utilised currently to evaluate the health effects of PREP use, potential biomarkers have been and are being developed for many of the relevant disease categories. The committee recommends further study of biomarkers for various disease categories that may potentially be determined to be intermediate indicators of disease and disease risk. For example, possible measures include markers of platelet and vascular activation, lipid peroxidation, and inflammation, which have the potential to be related to measures of cardiovascular physiology and, ultimately, reflect the risk of clinical cardiovascular disease as well as markers of inflammation in lung disease. Also, 
biomarkers of cancer that may indicate early carcinogenic processes and risk of cancer development include but are not limited to markers of genetic damage in blood, sputum, urine, and internal organs. Another potential marker is the measurement of bone density as a direct reflection of the severity and risk of osteoporosis.

Ideally, a set of behavioural markers is needed to monitor product use patterns, thereby enabling clinicians and researchers to measure substitution of PREP use for cessation. Although the committee realises the difficulty of developing a set of such behavioural markers, they are needed for a comprehensive evaluation of PREPs. A further detailed research strategy regarding the development of biomarkers can be found in the disease specific chapters (chapters 12-16) and the chapter on exposure and biomarkers assessment (chapter 11).

3. The evaluation of PREPs will be facilitated by the development of appropriate animal models and in vitro assays of the pathogenesis of tobacco attributable diseases.

Animal models and in vitro testing can contribute to the evaluation of individual PREPs and to the development of a scientific basis for designing and evaluating harm reduction products. Such studies could include cell culture, animal studies, and molecular studies to document specific toxicants as the most likely causative agents, to better define pathogenic effects of tobacco smoke exposure, to better explain the relationship of disease risk regression and exposure regression (doseresponse relationships), and to validate biomarkers of exposure and biological effect.

The new technologies of genomics and proteomics have the potential for evaluating and comparing the effects of tobacco exposure and PREP use on gene translation and expression in neoplastic and non-neoplastic disease.

The committee recommends specific applications of preclinical models for specific tobacco attributable disease. For example, the committee recommends the utilisation of genomic and proteomic technologies to investigate the effect on gene translation and expression of tobacco smoke exposure and its relevance for pulmonary, cardiovascular, and neoplastic health outcomes. Also, accurate models are needed for smoke or tobacco constituent exposure (including nicotine) and exposure to PREPs and their effects on the development of COPD, cardiovascular disease, neoplasia, and in utero injury. Again, a more detailed preclinical research agenda can be found in the disease specific chapters in section II (chapters 12-16).

4. Short term clinical and epidemiological studies in humans are required for the comprehensive evaluation of PREPS.

Some effects of PREPs in humans could be evaluated by epidemiological studies, by measurement of intermediate disease markers or, in some cases, by clinical studies of smokers who are unwilling or unable to quit but are willing to use PREPs (compared to a control group of conventional tobacco product users). The committee recommends the utilisation of validated intermediate biomarkers of disease effect in these studies in order to assess potential harm reduction within a practical time frame for diseases that occur only after prolonged exposure. Examples of potential measures include the use of lung function tests or inflammatory changes, evaluated through bronchoalveolar lavage, as intermediate markers for COPD in interventional studies.

A few smoking attributable diseases develop after relatively brief exposure (weeks to months) and provide an opportunity for strong short term clinical and epidemiological studies. These diseases include intrauterine growth retardation leading to low infant birthweight, slowed wound or ulcer healing, and perhaps acute myocardial infarction. Human studies are also required for evaluating the relationship of individual smoking history, environment, sex, race, and other factors (for example, diet) to disease risk and susceptibility. Further discussion regarding the utilisation of clinical studies can be found in section II (chapters 12-16).

\section{Long term epidemiological studies of} populations and/or pilot groups of users should monitor the incidence of disease or other adverse effects.

Most tobacco related diseases develop clinically over many years, and the only direct and definitive way to evaluate the harm reduction value of PREPs is to monitor the health outcomes of users compared to appropriate control groups over an extended period of time. Such surveillance could be an add-on to other epidemiological studies and should include ongoing reports of smoking behaviour, types of products used, and health outcomes, as well as intermittent collection of biological samples for biomarker assessment in a segment of users. Further discussion can be found in chapter 6 and in the disease specific chapters in section II (chapters 12-16).

\section{Risk assessment}

A report published in 1983 by a committee of the National Research Council outlined important steps and considerations in risk assessment. ${ }^{6}$ The "Red Book" identified important steps: hazard identification (does the toxicant cause the adverse effect?), dose-response assessment (what is the relationship between dose and incidence in humans?), exposure assessment (what exposures are currently experienced or anticipated under difference circumstances?), and risk characterisation (what is the estimated incidence of the adverse effect in a given population?). A risk characterisation provides important information for risk management, which also includes public health, social, economic, and political considerations.

The committee did not do a formal risk assessment of PREPs. The knowledge base is inadequate to do so at this time. However, the 
Table 2 Use of risk assessment framework in assessing tobacco harm reduction

\begin{tabular}{|c|c|c|c|c|c|}
\hline & Hazard identification & Dose response & Exposure assessment & Risk characterisation & Risk management \\
\hline $\begin{array}{l}\text { Information } \\
\text { required as } \\
\text { described in } 1983 \\
\text { "Red Book" }\end{array}$ & $\begin{array}{l}\text { Epidemiology; animal } \\
\text { bioassay; short term studies; } \\
\text { comparisons of molecular } \\
\text { structure }\end{array}$ & $\begin{array}{l}\text { Epidemiology; low dose } \\
\text { extrapolation; animal to human } \\
\text { extrapolation }\end{array}$ & $\begin{array}{l}\text { Dose to which humans are } \\
\text { exposed; dose of special } \\
\text { populations; estimation of } \\
\text { size of population potentially } \\
\text { exposed }\end{array}$ & $\begin{array}{l}\text { Estimate of the } \\
\text { magnitude of the public } \\
\text { health problem }\end{array}$ & $\begin{array}{l}\text { A risk assessment } \\
\text { (qualitative or } \\
\text { quantitative) may be } \\
\text { one of the bases of } \\
\text { risk management }\end{array}$ \\
\hline $\begin{array}{l}\text { Challenges in } \\
\text { risk assessment } \\
\text { of conventional } \\
\text { tobacco products }\end{array}$ & $\begin{array}{l}\text { Complex mixture; animal } \\
\text { models are limited; } \\
\text { constituents and additives are } \\
\text { proprietary information }\end{array}$ & $\begin{array}{l}\text { Dose changes for an individual } \\
\text { over time; dose of individual } \\
\text { toxicants varies over time; } \\
\text { exposure at time of disease } \\
\text { progression }\end{array}$ & $\begin{array}{l}\text { Changes in smoking } \\
\text { topography; complex } \\
\text { mixture }\end{array}$ & $\begin{array}{l}\text { For which disease? At } \\
\text { which point in smoking } \\
\text { history? }\end{array}$ & $\begin{array}{l}\text { FTC regarding } \\
\text { advertising }\end{array}$ \\
\hline $\begin{array}{l}\text { Additional } \\
\text { challenges of } \\
\text { PREP risk } \\
\text { assessment }\end{array}$ & $\begin{array}{l}\text { Tobacco related products will } \\
\text { change rapidly with time }\end{array}$ & $\begin{array}{l}\text { Assessing effect of moving } \\
\text { backwards on a dose exposure } \\
\text { curve, assuming long time } \\
\text { previous higher exposure }\end{array}$ & $\begin{array}{l}\text { Changing exposure after } \\
\text { long term higher dose } \\
\text { exposure; some toxicants } \\
\text { could increase }\end{array}$ & $\begin{array}{l}\text { Need models to consider } \\
\text { effects on initiation, } \\
\text { cessation, and relapse }\end{array}$ & $\begin{array}{l}\text { FDA authority } \\
\text { currently exerted only } \\
\text { over pharmaceutical } \\
\text { PREPs }\end{array}$ \\
\hline $\begin{array}{l}\text { Committee } \\
\text { charge }\end{array}$ & $\begin{array}{l}\text { 1. Does product decrease } \\
\text { exposure to the harmful } \\
\text { substances in or produced } \\
\text { during use of tobacco? }\end{array}$ & $\begin{array}{l}\text { 2. Is decreased exposure } \\
\text { associated with decreased harm } \\
\text { to health? } 3 \text {. Are there useful } \\
\text { surrogate indicators of disease } \\
\text { that could be used? }\end{array}$ & $\begin{array}{l}\text { 1. Does product decrease } \\
\text { exposure? }\end{array}$ & $\begin{array}{l}4 \text {. What are the public } \\
\text { health implications? }\end{array}$ & $\begin{array}{l}\text { 4. What are the } \\
\text { public health } \\
\text { implications? }\end{array}$ \\
\hline $\begin{array}{l}\text { Disease specific } \\
\text { summary data } \\
\text { (chapter 5; } \\
\text { section II) }\end{array}$ & $\begin{array}{l}\text { 3.Utility of preclinical research } \\
\text { to judge feasibility }\end{array}$ & $\begin{array}{l}\text { 1.Dose-response data for } \\
\text { conventional tobacco products } \\
2 \text {.Validation and development } \\
\text { of biomarkers } 4 \text {.Short term } \\
\text { clinical and epidemiological } \\
\text { studies }\end{array}$ & $\begin{array}{l}\text { 2.Validation and } \\
\text { development of biomarkers } \\
4 . \text { Short term clinical and } \\
\text { epidemiological studies }\end{array}$ & $\begin{array}{l}\text { 5. Long term } \\
\text { epidemiological studies } \\
\text { and surveillance }\end{array}$ & \\
\hline $\begin{array}{l}\text { Principal } \\
\text { conclusions }\end{array}$ & $\begin{array}{l}\text { 1. Risk reduction is feasible } \\
\text { 4. Exposure reduction can be } \\
\text { demonstrated }\end{array}$ & $\begin{array}{l}\text { 3. Surrogate measures could be } \\
\text { used to predict risk reduction }\end{array}$ & $\begin{array}{l}\text { 4. Exposure reduction can } \\
\text { be demonstrated }\end{array}$ & $\begin{array}{l}\text { 1. Risk reduction is } \\
\text { feasible } \\
2 . \text { Risk reduction not yet } \\
\text { demonstrated } \\
6 . \text { Public health impact } \\
\text { is unknown }\end{array}$ & $\begin{array}{l}\text { 5. Regulation is a } \\
\text { necessary } \\
\text { precondtion for } \\
\text { asuring a science base } \\
\text { and for assuring } \\
\text { protection of the } \\
\text { health of the public }\end{array}$ \\
\hline $\begin{array}{l}\text { Elements of } \\
\text { surveillance } \\
\text { system }\end{array}$ & $\begin{array}{l}\text { Specific tobacco constituents } \\
\text { of both the products and the } \\
\text { smoke they generate }\end{array}$ & Disease outcomes & $\begin{array}{l}\text { Consumption of tobacco } \\
\text { products and of PREPs; } \\
\text { biomarkers of exposure to } \\
\text { tobacco products; personal } \\
\text { tobacco product use and } \\
\text { related behavioural patterns }\end{array}$ & Disease outcomes & $\begin{array}{l}\text { Tobacco product } \\
\text { marketing, including } \\
\text { PREPs }\end{array}$ \\
\hline $\begin{array}{l}\text { Regulatory } \\
\text { principles (all } \\
\text { refer to tobacco } \\
\text { related PREPS, } \\
\text { except for } 11)\end{array}$ & $\begin{array}{l}\text { 1. Ingredient disclosure } \\
\text { 3. Preclinical testing required to } \\
\text { support health related claims } \\
\text { 7. Evidence for no increased } \\
\text { risk } \\
\text { 8. Added ingredient review } \\
\text { 9. Performance standards }\end{array}$ & $\begin{array}{l}\text { 6. Products with claims would } \\
\text { require postmarketing } \\
\text { surveillance and } \\
\text { epidemiological studies }\end{array}$ & $\begin{array}{l}\text { 2. Yield assessment } \\
\text { 4. With specific claims, no } \\
\text { increased exposure to } \\
\text { unclaimed compounds } \\
\text { 9. Performance standards } \\
\text { 11. Exposure reduction } \\
\text { claims for pharmaceutical } \\
\text { PREPs }\end{array}$ & $\begin{array}{l}\text { 5.Labelling for products } \\
\text { with claims cannot be } \\
\text { false or misleading }\end{array}$ & $\begin{array}{l}\text { 10. Enforcement } \\
\text { power }\end{array}$ \\
\hline Recommendations & $\begin{array}{l}\text { s3. Develop appropriate animal } \\
\text { models and in vitro assays of } \\
\text { pathogenesis }\end{array}$ & $\begin{array}{l}\text { 1. Sufficient data to allow } \\
\text { estimation of D-R } \\
\text { 2. Need to develop validated } \\
\text { biomarkers of disease }\end{array}$ & $\begin{array}{l}\text { 4. Clinical and } \\
\text { epidemiological studies in } \\
\text { human are required }\end{array}$ & $\begin{array}{l}\text { Comprehensive } \\
\text { surveillance is } \\
\text { recommended }\end{array}$ & $\begin{array}{l}\text { Regulation is } \\
\text { recommended }\end{array}$ \\
\hline
\end{tabular}

"Red Book" framework has great utility in presenting the committee's work. Table 2 uses it to summarise material discussed in chapters 1,5 , 6,7 , and 8. Even though the committee has concluded that harm reduction through the use of PREPs is not yet convincingly demonstrated, table 2 illustrates how the committee's conclusions and recommendations are key to gathering important data. This new knowledge base will permit a more definitive evaluation of harm reduction as a strategy and of PREPs as tools for reducing tobacco related morbidity and mortality.

Based on an extensive review of the scientific and medical literature, the committee concludes that although harm reduction is feasible, no currently available PREPs have been shown to be associated with biologically relevant exposure reduction or with decreased tobacco related harm. One narrow exception is the use of nicotine gum in one study for maintenance of cessation, described in chapters 8 ,
13, and 14. Without a comprehensive programme of scientific research, surveillance, and regulation, the potential benefit of harm reduction will go unrealised. Furthermore, without such a comprehensive programme PREPs could, in fact, be detrimental to both individual and public health.

1 Centers for Disease Control and Prevention. Cigarette smoking among adults-United States, 1998. MMWR Morb Mortal Wkly Rep 2000;49:881-4.

2 Public Health Service. Health, United States, 2000 with adolescent health chartbook. Hyattsville, Maryland: National Center for Health Statistics, 2000.

3 Centers for Disease Control and Prevention. Tobacco use among middle and high school students-United States, 1999. MMWR Morb Mortal Wkly Rep 2000;49:49-53.

4 Institute of Medicine. Lynch BS, Bonnie RJ, eds. Growing up tobacco free. Washington DC: National Academy Press, 1994.

5 Centers for Disease Control and Prevention. Health objective for the nation cigarette smoking among adultsUnited States, 1993. MMWR Morb Mortal Wkly Rep 1994:43:925-30.

6 National Research Council. 1983. Risk assessment in the federal government: managing the process. Washington DC: National Academy Press, 1983. 